Preference is given to letters commenting on contributions published recently in the JRSM. They should not exceed 300 words and should be typed double spaced

\section{Acute scrotum after myocardial infarction}

Mr Hamid and his colleagues (February 2003 JRSM $^{1}$ ) report a case of intratesticular haemorrhage after use of abciximab. Such incidents have been reported previously with other anticoagulants. ${ }^{2}$ Spontaneous haemorrhage should additionally be considered in the differential diagnosis of an acute scrotum even in the absence of underlying disease or concomitant anticoagulant administration. ${ }^{3}$ Furthermore, haematoma formation may not be restricted to the testis, having been reported at other sites including the spermatic cord. ${ }^{4}$ Of particular concern when making a presumptive diagnosis of haemorrhage is the association of bleeding with testicular neoplasms, the outcome of which can be critical if associated with a metastatic extension. ${ }^{5}$ In view of the limitations of ultrasonography, follow-up imaging is desirable, to ensure the absence of an underlying neoplasm.

\section{Tim Lane}

Urological Oncology, St Bartholomew's Hospital, London EC1A 7BE, UK

\section{Fiona Myint}

Royal Free Hospital, London, UK

\section{REFERENCES}

1 Hamid R, Arya M, Peters JL, Shah PJR. Acute scrotum after myocardial infarction. J R Soc Med 2003;96:80

2 Chong J, Flynn JT. Spontaneous anticoagulant-induced testicular haemorrhage mimicking a testicular tumour. BJU 1998;81:777

3 Evans KJ, Teddi RJ, Weatherby E. Spontaneous intratesticular hemorrhage masquerading as a testis tumor. J Urol 1985;134:1211

4 McKenney MG, Fietsam R Jr, Glover JL, Villalba M. Spermatic cord hematoma. Am Surg 1996;62:768-9

5 Motzer RJ, Bosl GJ. Hemorrhage: a complication of metastatic testicular choriocarcinoma. Urology 1987;30:119-22

\section{Homeopathic arnica}

The paper by Stevinson and co-workers (February 2003 $J R S M^{1}$ ) suggests that people undergoing carpal tunnel surgery are not helped by homeopathic arnica. The authors themselves describe the study as preliminary, and it has several important methodological flaws. To begin with, they failed to carry out a power calculation before conducting the research. They suggest that there were no reliable data on which to base a formal sample size calculation. However, they could have used the data from this pilot study to calculate a post-hoc power analysis in order to establish the robustness of their conclusions and determine the appropriate sample size for a full study.

Secondly, poor adherence to the treatment and the fact distributions are not presented in the paper) make it difficult to determine whether their results are influenced by outliers. Furthermore, Stevinson et al. do not report how outliers were dealt with, which is particularly relevant in small studies.

The researchers claim that the 'randomization procedure resulted in similar patient characteristics in each group for most variables', but they did not compare patient characteristics using statistical apalysis. In their Table 1 the preoperative pain for the arnica 6C group is reported as 3 , with a range of $0-70$. If this is not an error, then the patients in the arnica $6 \mathrm{C}$ group appear to be very different from the other two groups. The researchers also say that there were more male patients in the arnica $6 \mathrm{C}$ group. This suggests that there are systematic differences between the groups on characteristics that may have affected the outcome.

Furthermore, although the researchers report that oral analgesic medication (paracetamol or diclofenac) was prescribed, the actual use of these agents is not adequately presented in the study. Table 5 gives the numbers of tablets taken, but paracetamol and diclofenac (different types of analgesic) are grouped together, rather than presented separately, and details of dosages are not provided. This is a serious omission.

There is no doubt that rigorous studies are required to assess the usefulness and effectiveness of homeopathy. Unfortunately, rather than provide any clear evidence for or against the use of arnica postoperatively in carpal tunnel surgery, this article will simply be added to the list of homeopathic studies that raise questions about methodological rigour and practical relevance.

\section{Janet Richardson}

Chairman, Research Council for Complementary Medicine, 27a Devonshire Street, London W1G 6PN, UK

\section{REFERENCE}

1 Stevinson C, Devaraj VS, Fountain-Barber A, Hawkins S, Ernst E. Homeopathic arnica for prevention of pain and bruising: randomized placebo-controlled trial in hand surgery. $J$ R Soc Med 2003;96:60-5

Science and homeopathy are uneasy bedfellows. Despite the testimony of millions of people and the growing demand from both patients and doctors worldwide, scientists cannot understand how homeopathy works and therefore conclude that it does not.

The trial by Professor Ernst's group ${ }^{1}$ is open to criticism. The number of participants was small and it is doubtful if they took the medicine correctly. Although arnica 30C had no appreciable effect, the patients taking arnica 6C needed fewer painkillers - indicating, I would have thought, that arnica $6 \mathrm{C}$ was effective. The operation for carpal tunnel syndrome, if well done, results in very 
little swelling or bruising. Arnica is particularly efficacious where there is bruising and swelling. I used it for more than 30 years in my National Health Service practice for mothers after childbirth, and they would certainly testify to its effectiveness. Finally, in the Discussion section of the paper, the authors say that the trial did not rule out the possibility that individual patients could benefit from arnica. It would be a tragedy if this effective, non-toxic and inexpensive medicine was denied patients because scientists cannot believe that it works.

\section{J S Hughes-Games}

22 Duchess Road, Clifton, Bristol BS8 2LA, UK

\section{REFERENCE}

1 Stevinson C, Devaraj VS, Fountain-Barber A, Hawkins S, Ernst E. Homeopathic arnica for prevention of pain and bruising: randomized placebo-controlled trial in hand surgery. J R Soc Med 2003;96:60-5

In homeopathic proving studies, remedies are usually given to healthy individuals in $30 \mathrm{C}$ potency, twice a day, for one to two weeks. This usually triggers symptoms in susceptible individuals who 'prove'. These symptoms are then recorded by the homeopath and historically have formed the basis of the homeopathic materia medicas. When a patient is unwell, 'the remedy picture' described in the materia medica is then matched to the patient's symptoms and the most appropriate remedy selected, hence the term 'like cures like'. Stevinson et al. ${ }^{1}$ gave a potency and posology of arnica that, according to basic homeopathic principles, would be very likely to trigger a proving reaction either during or a few days after the operation. I am not aware that any of the individuals involved in the study was a practising homeopath so this may well be an oversight. It does, however, make the study very difficult to interpret; is it a proving study of arnica, in which case one would have expected the groups undergoing treatment to be worse than the controls, or is it a therapeutic study of arnica, in which case why would the investigators choose a 'proving dose'? This might represent a fundamental methodological flaw which could throw some doubt on the study's conclusions. Of course, the principles of homeopathic practice are unproven, but until we know whether they are correct or incorrect, we should certainly take note of them in studies designed to evaluate the effects of homeopathy.

\section{George Lewith}

Complementary Medicine Research Unit, Mail Point OPH, Royal South Hants Hospital, Brintons Terrace, Off St Mary's Road, Southampton SO14 OYG, UK

E-mail: GL3@soton.ac.uk

\section{REFERENCE}

1 Stevinson C, Devaraj VS, Fountain-Barker A, Hawkins S, Ernst E. Homeopathic arnica for prevention of pain and bruising: randomized placebo-controlled trial in hand surgery. JRSM 2003;96:60-5
Stevinson and her co-workers ${ }^{1}$ deal briefly with the issue of statistical power, stating that the lack of evidence from previous studies prevented them from carrying out a formal power calculation. They then argue that, since statistically significant effects have previously been observed in groups of 11-30 patients, a trial size of around 60, divided over three arms, should suffice for a preliminary study. What they signally fail to do is to follow the implications of their choice. A straightforward power calculation shows that so small a trial would have only a 1 in 4 chance of confirming the efficacy of such well-established conventional postoperative treatments as the use of tramadol for pain relief and ondansetron for nausea. Had the authors performed such a 'reality check', it would have put their negative finding in its proper context.

Furthermore - and contrary to the impression given by the authors - estimates of suitable trial sizes can be obtained even in the absence of prior insight into likely effect sizes. This is made possible by considering what constitutes a 'worthwhile' effect. A therapy that outperforms placebo in a high proportion of patients is clearly more worthwhile than one that does not. In quantitative terms, a worthwhile therapy is thus one requiring a relatively low 'number needed to treat' (NNT) - i.e. the number of patients who need to receive the therapy in order for it to benefit one patient. In the case of pain relief, for example, therapies with NNTs as high as 5 are still considered effective.

Taking an NNT of 5 to be a reasonable upper limit in the case of arnica leads directly to an estimate of appropriate trial size. Using standard statistical power theory, one can show that a randomized placebo-controlled trial needs around 100 patients per arm-i.e. a total of around 200 patients - in order to detect a clinically worthwhile effect with the standard $80 \%$ power. Smaller trials - all too common in complementary medicine- face a substantial risk of failing to detect worthwhile effects. One can show that a '50-50' rule applies, in which placebocontrolled trials with fewer than 50 patients per arm face a greater than $50 \%$ chance of failing to detect a worthwhile effect. This is not to say that small studies are worthless; when combined in a meta-analysis, they can provide useful insights. The fact remains, however, that the size of individual trials capable of detecting worthwhile effects is considerably larger than many seem to believe.

Certainly, if trials as small as those typically adopted in studies of complementary therapies had been used to assess the value of well-established conventional therapies, the shelves of hospital pharmacies would look decidedly bare.

\section{Robert A J Matthews}

Department of Information Engineering,

Aston University, Birmingham B4 7ET, UK 


\section{REFERENCE}

1 Stevinson C, Devaraj VS, Fountain-Barber A, Hawkins S, Ernst E. Homeopathic arnica for prevention of pain and bruising: randomized placebo-controlled trial in hand surgery. J R Soc Med 2003;96:60-5

The trial by Stevinson et al. ${ }^{1}$ was designed as a preliminary investigation but was analysed and reported as if it were a definitive trial.

The placebo group required $45 \%$ more postoperative analgesia than one of the verum groups (arnica 6C), a result which, if confirmed, is certainly clinically relevant. This verum group also had lower pain scores and, of course, these two variables are inversely related (i.e. for the same underlying pain level, patients taking more analgesia will report lower pain scores than those taking less). Analysing these variables separately therefore underestimates the effect size - in this case, the pain-reducing effect of arnica $6 \mathrm{C}$. This goes unremarked in the paper.

The CONSORT statement on the reporting of randomized trials calls for reporting of estimates of precision ( $95 \%$ confidence intervals), stating that 'They are especially valuable in relation to non-significant differences, for which they often indicate that the result does not rule out an important clinical difference'. ${ }^{2}$ Regrettably, Stevinson et al. do not report confidence intervals, and their trial came nowhere close to detecting statistical significance for the clinically very significant lower analgesia requirements in one of the active treatment groups.

In a preliminary investigation absence of proof should not be misinterpreted as proof of absence. By analysing the study as a definitive trial, the authors drew conclusions that it was not capable of delivering. Viewed as a feasibility study, it suggests that arnica 6C may be associated with useful benefits in terms of postoperative pain, a conclusion that accords with another published study. ${ }^{3}$ It could inform a larger study, including a sample size calculation, outcome measures and their timing.

Peter Fisher, Robert Mathie, ${ }^{1}$ Robbert van Haselen

Royal London Homoeopathic Hospital, Greenwell Street,

London W1W 5BP, UK; ' ${ }^{1}$ Faculty of Homoeopathy

\section{REFERENCES}

1 Stevinson C, Devaraj VS, Fountain-Barber A, Hawkins S, Ernst E. Homeopathic arnica for prevention of pain and bruising: randomized placebo-controlled trial in hand surgery. $J$ R Soc Med 2003;96:60-5

2 Altman DG, Schulz KF, Moher D, et al. The revised CONSORT statement for reporting of randomized trials: explanation and elaboration. Ann Intern Med 2001;134:663-4 [www.consortstatement.org]

3 Jeffrey SL, Belcher HJ. Use of Arnica to relieve pain after carpal-tunnel release surgery. Altern Ther Health Med 2002;8:66-8

\section{Author's reply}

If we do another arnica trial we certainly will (and others intending independent replications should) do a retrospective power calculation based on the data of our trial. We felt that it would have added little to the present study ${ }^{1}$ and also were very strapped for space.

Our study was an offshoot of a systematic review of all placebo-controlled trials of homeopathic arnica. ${ }^{2}$ This analysis included 8 such studies and concluded that 'the claim that homeopathic Arnica is efficacious beyond a placebo effect is not supported by rigorous clinical trials' . 2 German homeopaths later replicated this review and reluctantly conceded that 'efficacy ... . must be interpreted with utmost care'. ${ }^{3}$ I therefore feel that the results of our trial, which incidentally had a larger sample size than any previous arnica study, have to be seen in the context of previous research.

Dr Richardson refers to 'poor adherence'. In the actual article, we discuss why we feel reasonably certain that suboptimal adherence did not relevantly influence our results. A 'per protocol' analysis of our data would not have altered our principal finding. The fact that we don't mention exclusion of outliers obviously means that we did not exclude outliers. She suggests comparison of patient characteristics using statistical analysis, but this is not a legitimate approach. Clinical trials are not designed to test the hypothesis that two treatment groups are statistically different. Thus applying test statistics to this particular question is strictly speaking a misuse of statistics. Reviewing the baseline values in some detail, I find no reason to believe that the two groups were relevantly different or that the small existing differences influenced the result. It is true that in our article the use of rescue medication was only presented in a global fashion. More detailed analyses, we felt, were not justified as this was not a primary outcome measure. Reviewing these data in more detail, I see no reason to suspect that this confounded the results.

Dr Hughes-Games states that 'patients taking arnica 6C needed fewer painkillers'. This is not true. Our results show that they required an amount which was not statistically different from that of the other two groups. This commentator also believes our study was too small and then tells us anecdotes from his own clinical practice. Is a randomized trial of 62 patients really less conclusive than single case reports? I agree with Hughes-Games that it would be tragic to discard an effective treatment because of scientists' disbelief. But what about continuing to use an ineffective treatment because of homeopathic belief? The weight of the evidence ${ }^{1-3}$ strongly suggests that the latter is what we have been witnessing.

Dr Lewith makes several points which are easy to clarify. Ours was not, of course, a proving study but a therapeutic trial. We used two different doses (30C and 6C), thus his 
argument about a 'proving dose' does not really apply. The fact that some (by no means all) provings used a 30C dose certainly does not mean that $30 \mathrm{C}$ is not used therapeutically. We determined the two doses through consultations with homeopaths, and I am a trained homeopath myself. I therefore see neither the 'oversight' nor the 'methodological flaw' which Lewith points out. To imply that we neglected the principles of homeopathic practice can only be based on a lack of understanding of our study: in everyday homeopathic practice arnica is used in acute prescribing for tissue trauma, and this was the basis of our hypothesis.

Dr Matthews argues that NNT could have been used for a sample size calculation to determine a 'worthwhile' effect. In hindsight this makes sense to me, even though we would not have had the funds for a trial with 200 patients. Matthews also mentions that our trial could be valuable for a systematic review. I agree, and would add that the effect would be to make the findings from the two existing reviews ${ }^{2,3}$ even less encouraging than they already are.

Dr Fisher and his colleagues, in voicing suspicion that our trial was underpowered, cite a further trial (sample size $=37$ ) in support of their belief that, homeopathic arnica is, after all, effective. ${ }^{4}$ The cited study, however, was a trial not of homeopathic arnica alone but of arnica in combination with a herbal cream applied topically. The conclusion of our paper was, 'The results of this trial do not suggest that homeopathic arnica has an advantage over placebo in reducing postoperative pain, bruising and swelling in patients undergoing elective hand surgery'. I fail to see how we confused 'absence of proof' with 'proof of absence'.

\section{E Ernst}

Complementary Medicine, Peninsula Medical School, Universities of Exeter \& Plymouth, 25 Victoria Park Road, Exeter, Devon EX2 4NT, UK

\section{REFERENCES}

1 Stevinson C, Devaraj VS, Fountain-Barber A, Hawkins S, Ernst E. Homeopathic arnica for prevention of pain and bruising: randomized placebo-controlled trial in hand surgery. $J$ R Soc Med 2003;96:60-5

2 Ernst E, Pittler MH. Efficacy of homeopathic Arnica. A systematic review of placebo-controlled clinical trials. Arch Surg 1998;133:1187-90

3 Ludtke R, Wilkens J. Klinische Wirksambeitsstudien zu Arnica in homeopathischen Zubereitungen. In: Company Report. Essen: Carstens Stiftung, 1999

4 Jeffrey SL, Belcher HJ. Use of Arnica to relieve pain after carpal-tunnel release surgery. Altern Ther Health Med 2002;8:66-8

\section{Philosophy in medicine}

Dr Harper should be congratulated for his attempt to entice physicians to philosophical values (January $2003 \mathrm{JRSM}^{1}$ ). His article touches on several aspects of philosophy that can be viewed on a par with medicine. Philosophy (from the Greek for love of wisdom/knowledge) was the unifying theme in classical education. It encouraged the quest for why and how things come to be and provided a mechanism for reasoning that could be applied to any academic discipline. In modern times, when medicine is threatened by information-overload, the philosophical process (inquiry, critical reasoning, analysis) can offer valuable insights for practice. However, as Dr Harper indicates, acceptance demands an end to the misconception that philosophy is incompatible with practical science.

The general view is that, while science has answers that command widespread agreement, philosophy is interested in matters on which there is less consensus. By challenging concepts and assumptions, the philosophical approach can generate new perspectives in science. Advances in genomic biotechnology, for instance, illustrate the difficulty of deciding what to do with scientific discoveries. We need to consider what society we wish to have and our relationships with each other and our surroundings, which depend on our conception of ourselves as human beings at societal level.

This is where, in our opinion, Dr Harper's article is overambitious in scope. In trying to cover a large area, he omits certain issues that are important in explicating/ exploring the common ground between philosophy and medicine; for example, how should ethics be applied in the medical arena, or how does morality ethically connect with human society? His choice of philosophers was necessarily limited, but in an article about science as applied to medicine we would have included the following: Thales of Miletus, the first natural scientist and analytical philosopher in Western intellectual history; Aristotle, for his observation, methodological classification and empirical analysis; Bertrand Russell, for his logical analysis; ${ }^{2}$ and Michel Foucault, for his insightful analysis of scientific knowledge and social control. ${ }^{3}$

Andreas K Demetriades

Academic Department of Surgery, St Thomas' Hospital, London, UK

\section{Christina K Demetriades}

Department of Philosophy, University of Bristol, UK

\section{REFERENCES}

1 Harper CM. Philosophy for physicians. J R Soc Med 2003;96:40-5

2 Russell B. Human Knowledge. Its Scope and Limits. London: George Allen and Unwin, 1943

3 Foucault M. The Birth of the Clinic: an Archaeology of Medical Perception. London: Tavistock, 1973

\section{Prescription of neuraminidase inhibitors for influenza}

Mr Da Silva and colleagues' sensible paper on prescribing neuroaminidase inhibitors for influenza in general practice (February $2003 \mathrm{JRSM}^{1}$ ) attempts to put their use into a realistic context - i.e. those presenting within 36 hours of 
onset. Their results are nonetheless based on soft data. A considerable proportion of 'influenza-like illnesses' in patients of all ages are not due to influenza viruses (as Da Silva et al. acknowledge) and this proportion is liable to increase both when 'flu' is reported in the media as being present and when patients and doctors become aware that a cure may be available.

Hence, it will be very difficult to assess whether such drugs are genuinely useful in general practice unless one or more studies are done in which a diagnostic virus laboratory is used to confirm the cause in each case. Given the considerable practical difficulties of doing this, a wellprepared prospective study is necessary. In its absence, there is a danger of overprescribing; and, just as bad, overuse will discredit a useful group of drugs. It would be in the interest of the manufacturer(s) to sponsor such a study, as well as a search for a reliable and fast $(<1$ hour) test.

\section{Dick Madeley}

Burnfoot, Stocksfield NE43 7TN, UK

E-mail: dickmadeley@aol.com

\section{REFERENCE}

1 Da Silva PR, Nguyen-Van Tan J, Hayward AC. Logistic issues and potential prescribing costs associated with use of neuraminidase inhibitors for the treatment of influenza in primary care. $J R$ Soc Med 2003;96:66-9

\section{Legibility and authorship of clinical notes}

Dr Rodríguez-Vera and colleagues (November 2002 JRSM $^{1}$ ) report that $18(15 \%)$ of 117 clinical histories in a representative sample of case notes from a Spanish general hospital were illegible. Legibility was worse in records from surgical departments.
Another important issue is the manner in which the authors of clinical note entries identify themselves. The lack of a legible name, position and pager number identifying note entries has major implications in large and complex hospital systems where the case notes are an important means of communication between teams from different specialties. At the John Radcliffe Hospital between February and August 2002 we audited how well authors of note entries for patients on the colorectal surgical firm identified themselves, by looking for a legible name, rank and pager number. A total of 540 note entries in 20 patients made in 2002 were compared with 480 note entries made between 1995 and 1999 for the same group of patients. In the earlier series a legible name, rank and pager number were included in respectively 31\%, $29 \%$ and $49 \%$ of note entries, and this increased to $56 \%$, $49 \%$ and $72 \%$ in 2002. Although the new figures represent an improvement, they point to persistent deficiencies in the way authors of note entries identify themselves. We therefore support the conclusion of Rodríguez-Vera et al. that clinical notes should become computer based.

\section{A R Panigrahi}

Histopathology Department, Queen's Medical Centre, Nottingham NG7 2UH

\section{Cunningham}

Department of Colorectal Surgery, John Radcliffe Hospital, Headington, Oxford OX3 8DU, UK

\section{REFERENCE}

1 Rodríguez-Vera FJ, Marin Y, Sanchez A, Borrachero C, Pujol E. Illegible handwriting in medical records. J R Soc Med 2002;95:545-6 